\title{
PROFILE OF MEDICOLEGAL CASES; ACCIDENT \& EMERGENCY DEPARTMENT OF SERVICES HOSPITAL, LAHORE.
}

1. Associate Professor

Forensic Medicine \& Toxicology Department,

FMH College of Medicine and

Dentistry, Lahore

2. Senior Registrar Surgical Unit III,

Services Hospital, Lahore

3. Demonstrator Biochemistry Department,

FMH College of Medicine and Dentistry, Lahore

\section{Correspondence Address:}

Dr. Mariam Arif

Associate Professor

Forensic Medicine \& Toxicology

Department,

FMH College of Medicine and

Dentistry, Lahore

kemc51@yahoo.com

Article received on:

16/07/2016

Accepted for publication:

15/01/2017

Received after proof reading:

07/03/2017

\section{INTRODUCTION}

The accident and emergency department is the backbone of every tertiary hospital because all cases (of medical \& surgical emergencies) are reported first to this department. Therefore, this department plays a vital role not only in treating emergencies but also in catering to the legal needs of the cases. So medico legal cases constitute substantial proportion of workload in tertiary hospitals. ${ }^{1}$ These most commonly comprise of alleged cases of assault (physical \& sexual), road traffic accidents, burns, poisoning, industrial accidents, and alcoholic intoxications etc. $^{2}$

Medico legal case is a case of injury or ailment, where the attending doctor, after taking history and examining the patient, considers it necessary that an investigation by law enforcement agencies must be done to ascertain and fix the criminal responsibility for the case in accordance with the law of the land for the purpose of furthering of justice. ${ }^{3,4}$

Numerous studies have been conducted on the profile of medico-legal cases in various cities of Pakistan and also in neighboring countries, yet the pattern of medico-legal cases differ from region to region based on enforcement of law, socio-economic status and cultural norms of the land. ${ }^{2}$ Profiling of medicolegal cases is of utmost importance for reducing the resultant morbidity and mortality and to study the crime rate in area.

\section{OBJECTIVE}

The aim of the study is:

1. To study the pattern of medico- legal cases presenting to the accident and emergency department of Services Hospital, Lahore

2. To emphasize the need for implementation of effective preventive measures at national level. 


\section{MATERIAL AND METHODS}

This was a retrospective study extending over a one year period from $1^{\text {st }}$ January, 2014 to $31^{\text {st }}$ December, 2014 that included all the medicolegal cases brought to accident and emergency department of Services Hospital, Lahore. Individuals of all ages and gender were included and those with no medicolegal perspective were excluded from study. Relevant information was collected by reviewing medico-legal records from the medicolegal registers. A pre-tested structured proforma was used to collect the data regarding demographic profile and types of injuries. Data was analyzed using SPSS 14. This study was approved by the ethical committee of Services Institute of Medical Sciences, Lahore.

\section{RESULTS}

A total of 2166 individuals were brought for medicolegal examination to accident and emergency department during the study period. Out of these, majority of victims belonged to the age group $21-30$ years $(37.6 \%)$ followed by $31-40$ years $(23.3 \%)$ and $11-20$ years $(17.5 \%)$ respectively. The frequency of cases decreased beyond 50 years of age as shown in Table-l.
Males (83.6\%) outnumbered females (16.4\%) with a ratio of 5.1:1 (Table-I and Figure-1).

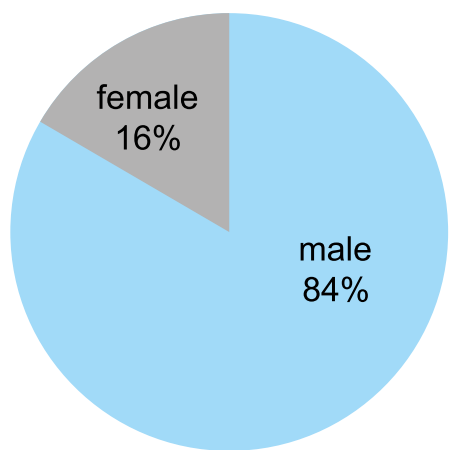

Figure-1. Gender wise distribution of medicolegal cases

Regarding the types of injury, almost two third of the victims suffered from blunt injuries 1403 $(64.77 \%)$ while firearm injuries $201(9.3 \%)$ and sharp weapon injuries 191(8.8\%) were second and third commonest type of injuries noted. The least common were burns $4(0.2 \%)$ and poisoning $12(0.55 \%)$. Cases of sexual assault were observed predominantly in females $111(63.8 \%)$ as shown in Table-II.

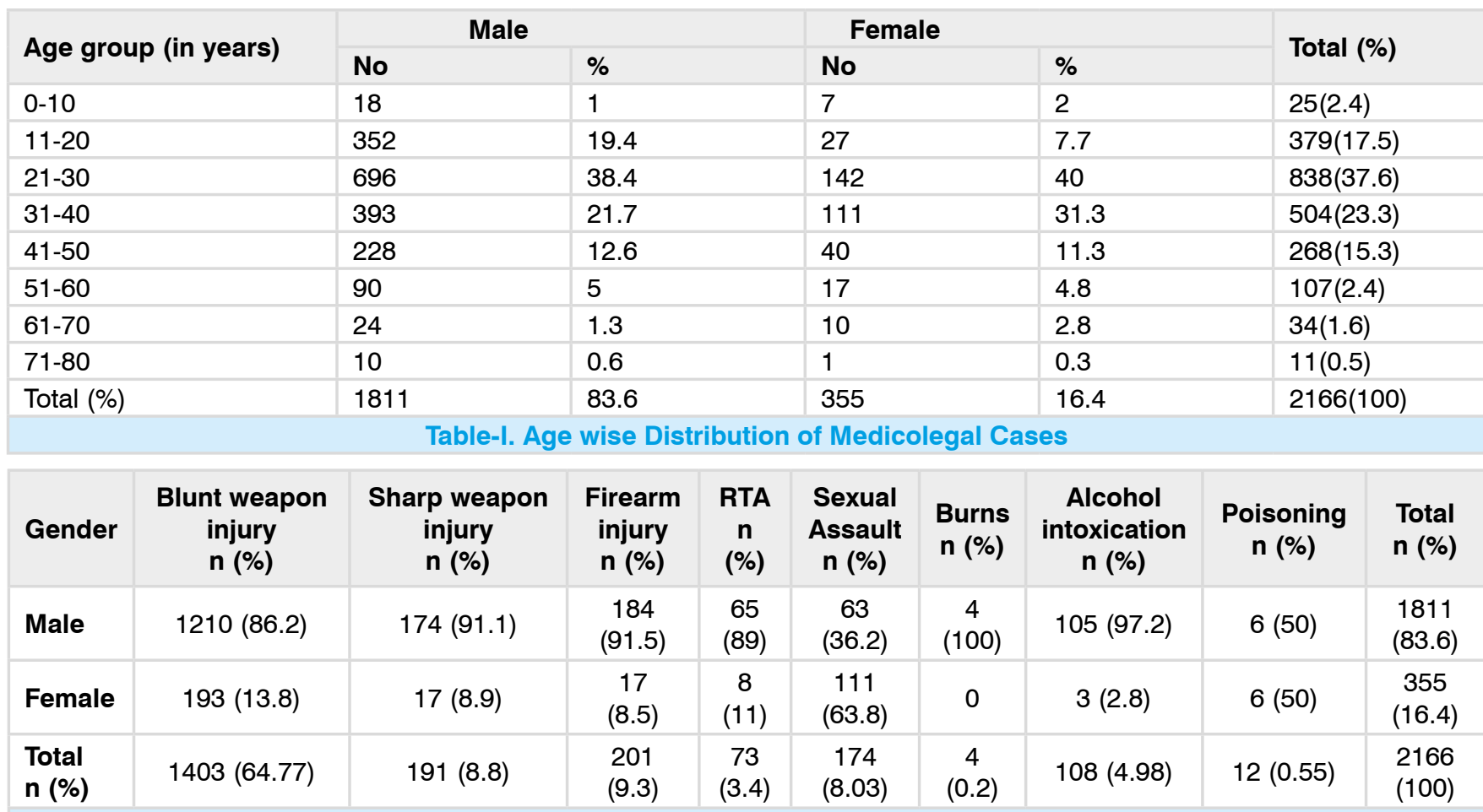

Table-II. Categories of Medicolegal Cases 


\section{DISCUSSION}

In this study males (83.6\%) were affected more than females (16.4\%) with a ratio of $5.1: 1$ which is comparable with observations of Bhatti $(5.9: 1)^{2}$ and Tajammul et al $(5.1: 1) .{ }^{5}$ Similar male preponderance was documented in other local studies by Marri6 as well as in international studies by Malik ${ }^{1}$ and Timsinha et al. $^{7}$ This is due to the fact that males are the breadwinners of the family and are more exposed to external environment thus making them more vulnerable to hazards of road, industry \& violence in the developing world. On the other hand, females are spared as they tend to stay at home engaged in household chores.

In our study, majority of cases belonged to age group 21-30 years (37.6\%) followed by $31-40$ years $(23.3 \%)$ constituting more than half of the total cases while there was decreasing incidence with increasing age. These findings are in line with those reported by Malik $\mathrm{Y}^{1}$, Bhatti ${ }^{2}$, Tajammul ${ }^{5}$ and Marri. ${ }^{6}$ The greater exposure to external environment, extrovert personality and more active life style with tendency to take undue risks make the youth more vulnerable to such hazards. Greater involvement of younger age group is of major concern as these people are the productive and most active members of our society. Besides high mortality rate, the injuries cause significant morbidity, long term physical and psychological disability for victims, families and societies. ${ }^{8,9}$ Moreover, the medical, legal and emotional costs of this violence impose an enormous burden on urban and rural hospitals. ${ }^{9}$

Blunt weapon injuries were most common in our study followed by firearm injuries (9.3\%) and sharp weapon injuries (8.8\%). All these cases of physical assault were observed mainly in males. This is consistent with other studies. ${ }^{1,2,5-10}$ Almost $90 \%$ male involvement in these cases is because they are more aggressive, emotional and provoked easily by any threat while females are introvert and shy and are less likely to pickup fights. The incidence of firearm injuries and sharp weapon injuries is considerably low in our study which is in accordance with other studies from Pakistan ${ }^{2,5,8,10}$ but is in contrast to studies conducted in western world ${ }^{10}$ The study conducted in UK reported prevalence of $86.8 \%$ penetrating trauma in urban areas. ${ }^{11}$ According to 2011 and 2010 local public health data, the annual count of firearm deaths and injuries in New York City exceeded 2000; there were 366 firearm fatalities, 999 firearm hospitalizations, and 691 firearm injury emergency department visits. ${ }^{12}$ Studies from the United States and other developed countries reported firearms usage in more than $60 \%$ of all homicides, over $25 \%$ of all assaults, more than $35 \%$ of all robberies and almost half of all suicides. ${ }^{13}$ Illegal possession of guns, male gender, and youth has been well documented as risk factors for firearm injuries. ${ }^{2,9}$ Low reporting in our study can be attributed to the fact that firearm related morbidity and mortality show wide regional variations globally depending upon the accessibility of firearms, socioeconomic status and law and order situation of the region. ${ }^{9}$

In our study, maximum cases of sexual assault were observed in females (63.8\%) as compared to males $(36.2 \%)$. Our finding is consistent with worldwide trends. The incidence is 225 rapes per 100,000 women in South Africa, 58 rapes per 100,000 women in United States and 22,000 rapes a year in India. ${ }^{14}$ In Pakistan, the rape rate is 16.8 per 100,000 women with $10 \%$ being gang rapes according to 2013 National Crime Data report. ${ }^{14}$ This situation is quite alarming. Sexual violence against women is a violation of our cultural and religious norms and indicates degradation of socio-cultural and moral values.

Studies from neighboring country reported that majority of the medicolegal cases were of road traffic accidents ${ }^{1,7}$ which is contrary to our study. Low reporting of road traffic accidents in this study may be due to the minor nature of the injuries inflicted which do not require inpatient care or treatment and mutual settlement of matters among parties without involving law and order agencies. These observations are consistent with other studies. ${ }^{2}$ 


\section{CONCLUSION}

Blunt weapon injury is the most frequently reported medico-legal offense in Services Hospital, Lahore followed by firearm injury and sharp weapon injury. There is a male predominance in all forms of these medico-legal cases except sexual assault which is more common in females.

Medico-legal cases have to be dealt with due care and proper attention following the institution's prevailing guidelines and instructions of Surgeon Medicolegal Punjab. Proper documentation, timely information, a methodical and thorough examination-including all relevant investigations and referrals, etc, is mandatory to see such cases through, successfully. Injuries can be prevented by proper education, awareness campaigns and strict implementation of law. In addition, improvement in health care facilities and post-traumatic care is of utmost importance in reducing the morbidity and mortality related to these injuries.

Copyright@ 15 Jan, 2017.

\section{REFERENCES}

1. Malik Y, Chawla R, Sharma G, Malik P, Singh R, Tripathi A. Profile of Medico-legal Cases in Casualty of a Rural Medical College of Haryana. J Indian Acad Forensic Med 2013; 35(4):367-368.

2. Bhatti MA, Mahmood S, Hanif S. Profile of Medicolegal Cases Attending Trauma Center Of District Headquarter Teaching Hospital, Gujranwala. Esculapio 2013; 9(3):146-149.

3. Sharma RK. Concise Textbook of Forensic Medicine \& Toxicology. $2^{\text {nd }}$ ed. Elsevier: A division of Reed Elsevier India Pvt Ltd, New Delhi; 2008.pp 92.

4. Krishan Vij. Textbook of Forensic Medicine and Toxicology: Principles and Practice, 4th ed. Elsevier: A division of Reed Elsevier India Pvt Ltd, New Delhi; 2008.pp 6.

5. Tajammul N, Chaudhary TH, Hanif H, Bhatti MA. Profile of Medicolegal Cases at Jinnah Hospital Lahore. Annals.2005; 2(3): 56-8.

6. Marri MZ, Baloch U. Frequency and Pattern of Medico Legal Cases Reported at Sandeman Civil Hospital Quetta Baluchistan-One Year Study. Medico-legal update $2011 ; 11(2)$ : 40-43.

7. Timsinha S, Kar SM, Baral MP, Ranjitkar M. Profile of Pattern of Medicolegal Cases in the Casualty of a Teaching Hospital of Western Region of Nepal. J Indian Acad Forensic Med 2015; 37(1):46-49.

8. Mirza FH, Hasan Q, Memon AA, Adil SE. Audit of sharp weapon deaths in Metropolis of Karachi- An Autopsy based study. J Ayub Med Coll Abbottabad 2010; 22(4): $66-9$.

9. Arif M, Rasool SH, Maqsood M. Morbidity and Mortality of Firearm Injury at a Tertiary Care Hospital in Lahore. JFJMC 2013; 7(4): 40-45.

10. Hassan $Q$, Bashir $M Z$, Shah MM. Physical Trauma -A Leading Cause of Medico Legal Cases at DHQ Hospital Abbottabad. J Ayub Med Coll Abbottabad 2010; 22(2): 156-159.

11. Crewdson K, Lockey D, Weaver A, Davies GE. Is the prevalence of deliberate penetrating trauma increasing in London? Experiences of an urban prehospital trauma service. Injury 2009; 40(5):560-3.

12. Firearm Deaths and Injuries in New York City, Epi Research Report, New York City Department of Health and Mental Hygiene April 2013.

13. Sachan R, Kumar A, Verma A. Frequency of Firearm Injuries, Deaths and Related Factors in Kanpur, India; an Original Study with Review of Literature. International Journal of Medical Toxicology and Forensic Medicine. 2013; 3(3): 88-95.

14. Arif M, Ahmed M. Medicolegal Analysis of Reported Cases of Alleged Rape in Multan- A Two Year Study. PJMHS 2014; 8(4):828-831.

\section{AUTHORSHIP AND CONTRIBUTION DECLARATION}

\begin{tabular}{|c|l|l|l|}
\hline Sr. \# & \multicolumn{1}{|c|}{ Author-s Full Name } & \multicolumn{1}{|c|}{ Contribution to the paper } & Author=s Signature \\
\hline 1 & Dr. Mariam Arif & $\begin{array}{l}\text { Prepared the proposal, data } \\
\text { collection and compilation, } \\
\text { manuscript writing } \\
\text { Data collection and compilation, } \\
\text { manuscript writing } \\
\text { Data collection, manuscript writing }\end{array}$ \\
\hline 3 & Dr. Syed Hamad Rasool & Dr. Syed M. Hammad Ali \\
\hline
\end{tabular}

